\title{
Vigilância e controle da comunicação no mundo do trabalho: manuais de
} conduta modelam a comunicaçã $0^{1}$

Roseli Figaro, Claudia Nonato \& Fernando Felícia Pachi Filho

\section{Resumo}

Este artigo tem por objetivo apresentar os aspectos teóricos e metodológicos de pesquisa realizada no Centro de Pesquisa em Comunicação e Trabalho da ECA-USP. 0 estudo pretende mapear e analisar os procedimentos técnicos e administrativos de empresas para monitorar, vigiar e controlar as relações de comunicação no mundo do trabalho, sobretudo, por meio das mídias sociais. 0 mapeamento está sendo realizado a partir da análise dos manuais de conduta de empresas privadas e públicas. Os resultados preliminares mostram a ambiguidade entre aqueles manuais que esclarecem a existência de controle e vigilância e aqueles que dissimulam tais procedimentos.

\section{Palavras-Chave}

Comunicação. Vigilância. Mundo do trabalho.

\section{Roseli Figaro | figaro@uol.com.br}

Professora Livre docente do Programa de Pós-graduação em Ciências da Comunicação da Universidade de São Paulo - USP, Brasil. Coordenadora do Grupo de Pesquisa Comunicação e Trabalho; pesquisadora do Núcleo de Pesquisa Comunicação e Censura da USP.

Claudia Nonato I claudia.nonato@uol.com.br Doutora em Ciências da Comunicação pela Universidade de São Paulo - USP, Brasil. É Pesquisadora do Centro de Pesquisa em Comunicação e Trabalho. Também atua como professora nos cursos de graduação em Comunicação da FIAM/FAM Centro Universitário.

Fernando Felícia Pachi Filho | ffpachi@yahoo.com.br Pós-doutorando pelo Centro de Pesquisa em Comunicação e Trabalho da ECA-USP, Brasil. É professor da Faculdade de Tecnologia Termomecânica (FTT) e da Universidade Paulista (Unip).

\section{Introdução}

A expressão ‘sociedade da vigilância' não é nova. Há inúmeros estudiosos do tema preocupados em entender como as tecnologias de comunicação e de informação têm sido utilizadas para capturar todo tipo de dados, e também para monitorar as relações de comunicação. Desde as imagens dos circuitos fechados de TV, câmeras em espaços públicos, a navegação por sites, quaisquer que sejam, até as palavras que digito agora em meu computador podem ser monitoradas e guardadas em um banco de dados gigantesco, em arquivos organizados e que são usados para desenhar perfis (Lyon, 2010, Bruno, 2006), acompanhar comportamentos e apontar tendências, tudo valendo muito dinheiro, além de as informações serem úteis para identificar e classificar os cidadãos potencialmente perigosos.

Grande parte dos pesquisadores faz uso das referências vigorosas de Michel Foucault (1999) sobre as formas de controle que as sociedades criam. A ideia do panóptico tem sido útil nesses casos, fazendo, inclusive, atualização dessa 
metáfora-conceito expandindo-a para fora das instituições, alcançando o ciberespaço (Bruno, 2006). Essa é a tradição com a qual dialoga um dos mais importantes pesquisadores do tema, David Lyon, em cuja revista Surveillance \& Society ${ }^{2}$, podemos acompanhar os avanços das pesquisas por meio de artigos de autoria de investigadores de várias tendências intelectuais.

\section{A pesquisadora brasileira Fernanda Bruno} define a vigilância digital como "monitoramento sistemático, automatizado e à distância de ações e informações de indivíduos no ciberespaço, com o fim de conhecer e intervir nas suas condutas e escolhas" (Bruno, 2008, p. 169; Bruno, 2006). A estudiosa procura conceituar as informações capturadas pelas redes, organizadas na forma de perfis característicos com a potencialidade de projetar tendências e propor ações de consumo em um amplo espectro de possibilidades. A funcionalidade dos sistemas de dados é a de caracterizar, formatar e orientar as ações de todos os que navegam pela internet e pelas redes sociais, à moda de um movimento antecipatório intermitente e de amplas possibilidades de uso, desde que seja rentável.

Outra tradição de análise vem dos estudos que discutem a herança do pensamento de Foucault na contemporaneidade, sobretudo na formulação do que este pensador chama de biopolítica (Foucault, 2000). Para Deleuze (1990), a análise de Foucault sobre a sociedade disciplinar se baseia na constituição de espaços fechados e na ordenação do tempo de trabalho. A sociedade do controle, por sua vez, teria como característica a interpenetração dos espaços, a ausência dos limites e a instauração de um tempo contínuo no qual os indivíduos estão enredados. Haveria uma regulação constante e universal da sociedade. Nessa perspectiva, para Costa, "nenhuma forma de poder parece ser tão sofisticada quanto aquela que regula os elementos imateriais de uma sociedade: informação, conhecimento e comunicação"(2004,p.163).

Mas nossa chegada ao tema se deu por outro caminho. Deu-se pela trajetória de nossos estudos sobre a censura nos períodos ditatoriais no Brasil, em Portugal, na Espanha e na Itália. Nela, está registrada vasta produção de um conjunto de pesquisadores, resultado de investigações no Arquivo Miroel Silveira e no Observatório de Comunicação, Liberdade de Expressão e Censura - $0 \mathrm{BCOM}^{3}$, em abordagens diversas que privilegiam aspectos da história e da cultura e consideram as condições em que a censura ocorre nessas sociedades. Nesse percurso,

A primeira versão deste artigo foi apresentada, como relato de pesquisa, ao III Simpósio Internacional da Rede Latino-Americana de Estudos em Vigilância, Tecnologia e Sociedade/LAVITS 2015, Brasil, e contou com a colaboração da bolsista de iniciação científica Laila de Albuquerque Moraes.

Disponível em : http://library.queensu.ca/ojs/index.php/surveillance-and-society/index Acesso 11/09/2015.

Disponível em : www.obcom.nap.usp.br 
nos deparamos com o cerceamento à liberdade de expressã $0^{4}$ no mundo do trabalho $0^{5}$, tendo como objeto de estudo matérias dos meios de comunicação, noticiando demissões de trabalhadores por eles terem se manifestado, segundo as empresas, inadequadamente na internet. Deu-se aí a aproximação de duas abordagens de pesquisa: 0 estudo da censura, do controle e da vigilância com os estudos da comunicação no mundo do trabalho $0^{6}$.

Nossa perspectiva de pesquisa aponta para a hipótese de que as empresas não toleram administrar a expressão simbólica dos trabalhadores que, segundo sua perspectiva, prejudicaria a ordem e a imagem das organizações. Por outro lado, essas mesmas organizações precisam captar o potencial comunicacional dos trabalhadores em proveito da produtividade e da competitividade. Desse modo, para as empresas, a expressão dos trabalhadores é um item a ser considerado e controlado.

Em contradição à almejada horizontalidade das relações e dos acessos, temos um mundo do trabalho altamente controlado e vigiado tal qual, ou até mesmo em escala superior, aos antigos controles das fábricas taylorizadas. Para Sennet,
"A repulsa à rotina burocrática e a busca da flexibilidade produziram novas estruturas de poder e controle, em vez de criarem as condições que nos libertam". (2012:52)

Neste artigo, nosso objetivo é apresentar e problematizar alguns aspectos da pesquisa "Comunicação e Trabalho. Manuais de conduta das empresas como prescrição, controle e vigilância da liberdade de expressão no mundo do trabalho", realizada por pesquisadores do Centro de Pesquisa em Comunicação e Trabalho da ECA-USP. Essa investigação pretende mapear e analisar os procedimentos técnicos e administrativos de empresas para monitorar, vigiar e controlar as relações de comunicação no mundo do trabalho, sobretudo, por meio das mídias sociais. 0 mapeamento está sendo realizado a partir da análise dos manuais de conduta de 50 empresas, buscados na internet por meio dos termos-chave: "Código de conduta", "Código de ética" e "Manual de conduta".

A partir da leitura e da análise dos documentos, fazemos a classificação dos respectivos manuais e, por fim, pretende-se realizar algumas reflexões sobre 0 direito à liberdade de expressão e seus limites no mundo do trabalho.

Entende-se liberdade de expressão como direito fundamental regulado pela Constituição Brasileira de 1988, conforme consta em seu artigo 5. Item IX "é livre a expressão da atividade intelectual, artística, científica e de comunicação, independentemente de censura ou licença”. Disponível em: http://www.planalto.gov.br/ccivil_03/Constituicao/Constituicao.htm Acesso: 12/09/2015.

5 As pesquisas sobre a comunicação no mundo do trabalho estão publicadas em dezenas de artigos em revistas científicas da área da Comunicação. Entre os livros, destacamos: Relações de Comunicação no mundo do trabalho, 2008; e As mudanças no mundo do trabalho do jornalista (2013).

6 Dois últimos artigos sobre o tema estão publicados nos livros organizados por COSTA, Cristina (org.). A censura em debate. São Paulo: ECA-USP, 2014. . Diálogos sobre censura e liberdade de expressão. Brasil e Portugal. São Paulo: ECA-USP, 2014. 


\section{Vigilância e controle da comunicação na empresa e no mundo do trabalho}

0 estudo da vigilância e do controle à liberdade de expressão no mundo do trabalho se justifica porque é do trabalho e por meio dele que os aparatos tecnológicos são introduzidos em nossas vidas. Todos os aparatos tecnológicos estão envolvidos pela lógica de facilitar a vida e as relações entre as pessoas no que diz respeito ao trabalho e à comunicação, ultrapassando as infidelidades do tempo e do espaço. Mais do que isso, as tecnologias são, antes de tudo, pensadas na dimensão da produtividade e da competitividade (SANTOS, 2000) em um processo em que as ciências são instrumentalizadas para atender ao regime produtivo, processo já identificado por Marx (1980) e por Weber (1999). Álvaro Vieira Pinto, no livro Conceito de tecnologia (2005), reafirma a determinação humana na criação e no uso das tecnologias, embora sejam apoderadas pelos imperativos dominantes.

No âmbito do mundo do trabalho, softwares, algoritmos, câmeras, cartões de identificação perseguem os rastros dos trabalhadores, tornando-os potenciais produtores de conteúdo, consumidores, líderes ou personagens perigosos. Tais dispositivos, portanto, constroem sujeitos diversos para os trabalhadores, que se tornam colaboradores ou ameaça, conforme a orientação programada. A empresa, no afã de defender sua imagem, otimizar processos e tempos de trabalho, bem como conquistar novos consumidores, tem adotado métodos, sistemas e contratado profissionais para o trabalho de monitoramento da comunicação interna e externa à corporação. Há a formação de departamentos e de setores na estrutura da empresa responsáveis pelo controle e, muitas vezes, são profissionais da comunicação a desempenhar o papel de vigilante e controlador. Nestas práticas que se generalizam, a manutenção da 'ordem' entra em colisão com a liberdade de expressão, procurando restringi-la. Entra em linha de colisão também com o papel social do profissional de comunicação aquele que deveria cumprir a função de garantir o direito à informação, aspecto fundamental do perfil destes profissionais.

Nesse contexto, há empresas mais prudentes que adotam procedimentos para dar ciência a seus funcionários da existência de um manual de conduta, de regras de comportamento comunicacional a serem seguidas, avisando-os e orientando-os sobre a vigilância (Andrelo, Matos, 2014). Mesmo essas, têm adotado a prática de invadir mensagens particulares, em endereços eletrônicos particulares, para 'garantir' o direito delas à 'boa' imagem. Outras ainda cerceiam 0 acesso a determinados conteúdos, imputando-os previamente quando não adequados à imagem da empresa. Busca-se, portanto, naturalizar as práticas de controle, inserindo-as em uma ordem discursiva prevista nas regras a serem seguidas nas atividades de trabalho. A liberdade de 
expressão, positivada como direito fundamental do cidadão, perde sua autonomia e fica em função do regime de trabalho. Desse modo, intensifica-se a contradição entre um sujeito juridicamente livre, porém responsável (Orlandi, 2001), e submetido a ordens diversas que 0 cerceiam. Como alerta Barry (2007), as práticas de controle corroem as liberdades democráticas e inibem a formação da opinião pública.

Na perspectiva de Max Weber, as normas e regulamentos (os manuais) são característicos da burocracia, uma "organização eficiente por excelência" (Chiavenato, 1995). Segundo o autor, para conseguir maior eficiência, a burocracia precisa detalhar antecipadamente e nas minúcias como as coisas deverão ser feitas, fato que leva à elaboração de documentos que "conferem às pessoas investidas da autoridade um poder de coação sobre os subordinados e também os meios coercitivos capazes de impor a disciplina" (p.263), assegurando assim uma interpretação única e padronizada. Além disso, para Weber, a burocracia é ligada por comunicações escritas, para comprovar e documentar as regras, decisões e ações administrativas. Desse modo, "a interpretação unívoca das comunicações também é assegurada" (idem), pois a burocracia lança mão de rotinas e de formulários para facilitar as comunicações e para rotinizar o preenchimento de sua formalização.

Conquanto as teorias sobre a organização burocrática da empresa desdenhem 0 conjunto humano que dá existência ao mundo do trabalho, nossos estudos têm demonstrado como o mundo do trabalho é ambiente complexo e mais amplo, com lógica própria e diferente da estabelecida pelo corpo dirigente da empresa. Mesmo as abordagens das Relações Públicas que tratam as empresas e seus públicos têm limitações já bem discutidas, a exemplo de Rebechi (2014) que analisa, em sua tese de doutorado, os procedimentos lineares da comunicação organizacional como parte da racionalização dos métodos e processos de trabalho.

Para os estudiosos das situações de trabalho, as normas e as prescrições são necessárias, pois registram o percurso do trabalho daqueles que pensaram e realizaram antes (Schwartz, Durrive, 2007). As prescrições e as normas são orientações, mas o trabalho vai além das normas, faz a gestão do inédito, do real da atividade, no momento mesmo da ação, e, com isso, atualiza a norma, tornando-a prescrição para os outros, sempre no movimento dialético do fazer e refazerse em outro nível.

Dessa forma, ao compararmos a estrutura da organização com o mundo do trabalho, compreende-se a disjunção ali existente, o jogo de forças que se estabelece e como os interesses e objetivos são diferentes (Figaro, 2008a). A comunicação no mundo do trabalho, portanto, vai além e por outros caminhos daqueles da comunicação dita organizacional. 0 lugar e 0 tempo do trabalho necessitam das relações de comunicação para se constituírem. 0 corpo, 0 
movimento, os olhares e as palavras trabalham, atuam no desempenho da produção. Arantes (2015), em sua pesquisa de doutorado, estudou as relações de comunicação em fábricas recuperadas por trabalhadores e utiliza-se dessa concepção diferenciada de empresa e mundo do trabalho para situar seu objeto de estudo. Opera o conceito de linguagem como trabalho de Rossi-Landi (1985) e as noções de comunicação no, como e sobre 0 trabalho de Lacoste (1995). Ou seja, o pesquisador comprova 0 gap entre a prescrição para 0 trabalho e a comunicação no mundo do trabalho.

A exemplo desses dois autores, as pesquisas sobre as relações de comunicação no mundo do trabalho (2008b) têm demonstrado quanto a comunicação é relevante no e como trabalho. E nos faz problematizar de que maneira a vigilância e 0 controle podem ser cerceadores da comunicação. Sendo assim, interessa-nos discutir os manuais de conduta como prescrição de comunicação da empresa para os empregados. 0 que os manuais prescrevem? Quais são as regras e as determinações sobre 0 que fazer e 0 que não fazer? Como se dá a vigilância, o controle e, quem sabe, haverá censura, sanções aos atos avaliados como inapropriados?

A compreensão sobre as configurações adquiridas pela vigilância, pelo controle e pelo cerceamento da comunicação considera que essas formas estão dadas pelas relações econômicas e de poder estabelecidas na sociedade. No caso presente, a sociedade global, conectada e em rede não se constitui como o sonho da 'aldeia global'. Muito ao contrário, a concentração econômica e de poder nunca foi tão forte, e a ciência é incorporada como técnica (Santos e Silveira, 2001) a serviço da manutenção do status quo. As informações tornadas públicas pelo ex-administrador de sistemas da CIA e ex-contratado da Agência Nacional de Segurança dos Estados Unidos (NSA), Edward Snowden, e pelo site Wikileaks revelam os caminhos que preferem trilhar os que têm poder.

Nesse sentido, a vigilância e 0 controle no mundo do trabalho estão orientados em larga escala para a manutenção da ordem econômica e da concentração de poder; no micro do trabalho, vigilância e controle são formas de domesticar e de extrair informações para criar ou inibir expectativas de ações sobre as quais há estratégias de antecipação.

\section{Do silenciamento aos manuais de vigilância e controle}

No século XX, até a Constituição cidadã de 1988, a censura foi uma instituição balizada pelo Estado brasileiro, organizada como repartição pública, instalada em Secretaria de Estado de Segurança Pública. Hoje, essa estrutura não mais existe. As formas de controle da produção cultural e comunicacional tomaram outros caminhos. Por outro lado, as empresas adotam estratégias para monitorar, vigiar, invadir e controlar o uso da internet por seus empregados. As mídias sociais dominam o fluxo da comunicação interpessoal 
mediada por tecnologia digital e exploram 0 trabalho coletivo (Fuchs, 2012) de bilhões de pessoas que produzem conteúdo e fornecem seus dados pessoais, hábitos de consumo, informações sobre os relacionamentos com amigos e familiares.

Desse modo, a censura prévia aos moldes do século XX torna-se completamente inoperante. Ela perde seu centro e se torna mais difusa. 0s mecanismos de vigilância e interdição são ampliados e dissimulados nas práticas rotineiras, especialmente no mundo do trabalho, tendo se naturalizado em nome da segurança e da preservação da imagem das organizações.

Conforme discutido em estudo anterior (2014), 0 mundo do trabalho sempre foi vigiado e controlado pelas empresas. Sobre esse tema, ressaltamos a apropriação das pesquisas da sociolinguista Josiane Boutet (2008):

Boutet (2008), em seu estudo sobre a vida verbal no trabalho, retoma Friedrich Engels ( $A$ situação da classe operária na Inglaterra, 1845) e, depois, Jacques Le Goff (Du silence travail à la parole,1988) para afirmar a soberania do patrão no espaço do trabalho. 0 empresário é 0 legislador absoluto, impõe inclusive as regras verbais e a interdição da fala no mundo do trabalho. Boutet (2008, p.27) estuda os regulamentos afixados nas empresas pelos patrões. A Biblioteca Nacional Francesa tem uma coleção desses documentos, são 354 "Règlements d'atelier 17981936" (Regulamentos de oficina) que mostram a prática dos industriais em regulamentar 0 uso do corpo, do espaço e da palavra pelos trabalhadores, bem como impor multas aos insubordinados. A sociolinguista classifica as interdições enunciadas naqueles documentos em dois tipos: 1) interditos de natureza produtiva, são impedimentos da palavra (sobretudo aquela dirigida ao outro) e de todas as outras formas de expressão, cantar, assoviar, para garantir maior produtividade e impedir a organização dos trabalhadores; 2) Interditos de natureza moral, ou seja, a denominada expressão verbal operária, e a denominada transgressão das normas de civilidade. (FIGARO, 2014, p.36-37)

Guardadas as devidas diferenças de espaço e tempo, parece que os manuais de conduta não se distanciam tanto dos Règlements d'atelier. A questão do direito à palavra no mundo do trabalho e, hoje, 0 direito à livre expressão é quase um privilégio daqueles cujas relações de trabalho não estão subordinadas à marca de uma empresa. Privilégio, porque até mesmo 0 acesso à internet é restrito a uma parte dos trabalhadores e, mesmo assim, existem procedimentos limitadores à troca de informações. 0 direito se torna privilégio, a expressão é regrada, erigindo-se uma barreira entre quem pode se expressar e quem não pode, porque está submetido a uma ordem discursiva, no caso 0 contrato de trabalho, o qual impede a interpretação e a tomada de posições, conforme explica Orlandi (1998) no seu estudo sobre silêncio.

Segundo pesquisa realizada, pelo Centro de Estudos sobre as Tecnologias de Informação e Comunicação, do Comitê Gestor da Internet Brasil, CGI.br, denominada TIC Domicílio e Empresas 2013, a proporção de empresas com política de restrição de acesso a sites específicos na internet ainda é muito expressiva. Entre as empresas de maior porte, ou seja, com mais de 250 
empregados, a restrição a sites pornográficos é de 95\%; a restrição a jogos chega a 90\%; a restrição a redes sociais é de $86 \%$. No que diz respeito a sites específicos, $62 \%$ das empresas de mais de 250 empregados restringem acesso a notícias, entretenimento e esportes; $60 \%$ delas restringem acesso a email pessoal; e $59 \%$ restringem acesso a serviços de comunicação. Chama a atenção 0 fato de as empresas do ramo de informação e comunicação serem também altamente restritivas quanto ao acesso à internet por seus empregados. Conforme a pesquisa do CGI.br, 53\% dessas empresas restringem acesso às redes sociais; $80 \%$ delas impedem acesso a temas pornográficos; 34\% impedem acesso ao email pessoal e 33\% impedem acesso a serviços de comunicação.

Além desse tipo de restrição, empresas de comunicação como a Folha de S. Paulo, Rede Globo, Wall Street Journal e New York Times têm criado regras restritivas ao uso das redes sociais por seus jornalistas, bem como criado uma normatividade de como o funcionário pode aparecer no espaço público das redes sociais. Essas práticas têm suscitado discussões sobre se é ou não direito da corporação controlar o uso dos meios virtuais de comunicação; e se essa prática se constitui em censura ou não. Um caso exemplar é o do jornalista Felipe Milanez, ex-editor da revista National Geographic Brasil, que foi demitido por comentar, em sua conta no Twitter, matéria de um dos veículos de seu empregador, a revista Veja, sobre xenofobia em relação aos índios bolivianos ${ }^{7}$. Ou seja, o jornalista, por ser funcionário da empresa, não pode expressar sua opinião contrária à xenofobia, conforme direito fundamental regido pela Constituição! Como denominamos tais ações por parte das empresas? A Justiça tem julgado a favor delas e mantido demissões por justa causa, em que 0 trabalhador perde todos os seus direitos trabalhistas. As relações de trabalho, portanto, se projetam no espaço público, sobredeterminando os direitos individuais, que se submetem à ordem do capital. Neste aspecto, o sujeito trabalhador se confunde com o sujeito cidadão, e ambos se subordinam às regras do contrato de trabalho. 0 s conflitos derivados de posições assumidas no tocante ao debate público, como no caso de Milanez, também ficam submetidos ao poder manifesto da empresa.

Será que as empresas, por meio de seus manuais de conduta, desenvolvem procedimentos e rotinas de trabalho que podem revelar como instituem o controle e a vigilância, quiçá os caminhos da renovação do conceito de censura? Se vivemos agora em uma democracia como o Brasil nunca havia experimentado, certamente a sociedade aspira à ampliação desse espaço democrático. Almeja maior participação, o que redunda em novos moldes de organização da representação social, e implica a compreensão de quais são os 
mecanismos atuais que seguram e impedem 0 alargamento da participação e a consolidação dos direitos democráticos. Não podemos nos esquecer que a palavra "censura", a se vincular aos períodos ditatoriais e colidir com os direitos fundamentais na ordem democrática, se torna "proibida" no discurso social. Assumir práticas de controle como práticas de censura significa alinhar-se a uma memória que evoca sentidos negativos, o que não é o desejo das organizações. No entanto, isso não quer dizer que a censura como prática cultural tenha desaparecido, ela se desloca e se ressignifica na dimensão do controle e da vigilância, práticas aceitas como indispensáveis na gestão das organizações. Fuchs (2012) afirma ser improvável que 0 sistema do capital abra mão da vigilância dos cidadãos e reitera o pensamento de Marx ao estudar a vigilância como inerente ao capitalismo. Nossa pesquisa colabora para se entender as formas organizativas a partir das quais a vigilância e o controle se estabelecem como aspectos rotineiros e naturalizados da vida em sociedade, sobretudo quando essas ações vêm do mundo do trabalho e se tornam cristalizadas como normas sociais. A pesquisa aponta que, para mais além do controle e da vigilância como lógica da dissimulação e dispersão das estruturas de poder, há, por parte das instituições empresariais, enquadramentos bem determinados sobre os formatos e os conteúdos de comunicação permitidos a seus empregados.

\section{Manuais de conduta como objeto de estudo da vigilância e do controle no mundo do trabalho}

0 mapeamento e análise partem de uma amostra de manuais de conduta de 50 grandes e médias empresas brasileiras de setores econômicos diferentes. Em estudo exploratório, levantamos e analisamos sete desses manuais de grandes e médias empresas nacionais e estrangeiras e verificamos a pertinência de nossa hipótese de estudo ${ }^{8}$. Dando prosseguimento à pesquisa, os 50 manuais de conduta foram buscados na internet, por meio de palavras-chave, no sistema Google de busca. As palavras-chave utilizadas no site de buscas foram, principalmente, "Código de conduta", "Código de ética" e "Manual de conduta". Cumpre destacar que os manuais de conduta visam estabelecer normas que se tornam padrões de racionalidade e de ação, para os quais não há contestação ou elaboração conjunta entre empresas e trabalhadores.

É relevante explicar que a falta de acesso aos Manuais de conduta das empresas foi uma das dificuldades encontradas ao longo da pesquisa, primeiro, porque poucos estão disponíveis na internet e, segundo, por conta do uso de termos distintos utilizados pelas empresas para se referir aos manuais. E, apesar de distintas denominações, a análise dos manuais não confirmou nenhum padrão para se utilizar um ou 
outro nome, sendo assim, na prática, o que ocorre é uma confusão de termos.

Para efeitos de análise, os manuais foram separados em dois tipos de classificações distintas. A primeira delas é para identificar se o manual abrange ou não mídias sociais, sendo que as respostas possíveis são: muito, quando o manual é específico para as mídias sociais; pouco, quando ele se resume a uma parte do manual de conduta não específico para mídias sociais; e nada, quando o manual não cita mídias sociais. A segunda classificação é para identificar se o manual apresenta forte indicativo de controle de informação ou não, sobretudo, o controle da informação nas mídias sociais. Observa-se ainda que grande parte dos manuais das instituições escolhidas para estudo não esclarece o que significam as formas de monitoramento da informação e nem mesmo quais são os direitos dos usuários em relação aos respectivos instrumentos e/ou veículos de informação $0^{9}$. Desse modo, a organização procura se sobrepor aos direitos individuais pela adesão a códigos de conduta, enfeixando o trabalhador em uma rede de padrões que, por definição, inibem sua expressão e coíbem a fala livre.

\section{Análises preliminares}

A partir da análise preliminar dos dados coletados, chegamos à conclusão de que $50 \%$ dos manuais de conduta selecionados (25, do total de 50) não mencionam nem usam referências sobre a utilização da mídia social na empresa. Entre aqueles que 0 fazem, 13 apresentam informações sobre 0 uso da internet, não fazendo comentários específicos sobre as redes sociais e aos aplicativos de mensagens instantâneas.

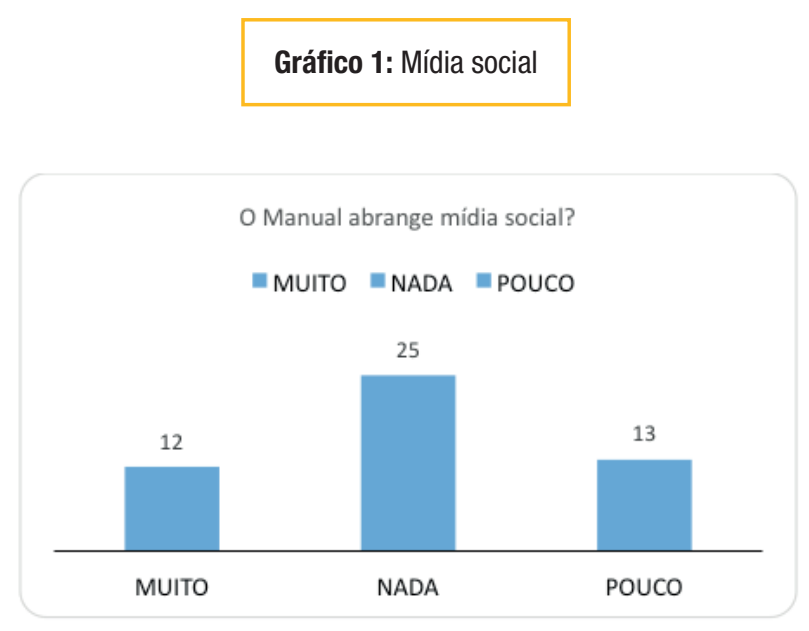

Fonte: Pesquisa Comunicação e Trabalho. Manuais de conduta das empresas como prescrição, controle e vigilância da liberdade de expressão no mundo do trabalho.

As 50 instituições públicas e privadas cujos Manuais de conduta foram analisados são: Akzo Nobel, Ambev, Arezzo, Braskem, Cargill, Claro, Carrefour, Coca-cola, Dell, Eletrobras, Embrapa, Embraer, Febraban, Fiat, Fibria, Gerdau, Gol, Grupo Abril, Grupo Informe, Grupo Máquina, Grupo Pão de Açúcar, Grupo RBS, GVT, Hypermarcas, Ibope, Intel, Infraero, Itaú, Klabin, Leão Alimentos e Bebidas, 3 M, Magazine Luiza, Marisa, Ministério da Defesa, 0 Boticário, Odebrecht, Oi, P \& G, Petrobras, Polishop, Raízen, Sabesp, Sadia, TAM, Vale, Votorantim, Volkswagen, Volvo. 
Além disso, 40 dos manuais de conduta

selecionados não apresentam indicativo direto de que as instituições estariam controlando as informações dos funcionários. As instituições que 0 fazem dão informações evidentes de que há monitoramento das informações e controle dos ambientes digitais, além de não darem garantia de privacidade nesse meio.

Na análise dos manuais de conduta, foi observada a preocupação das instituições com a preservação de sua imagem, ao tentar impedir 0 vazamento de dados confidenciais e ao sugerir - ou mesmo coagir - seus funcionários a não se exporem demais nas mídias sociais para que não prejudiquem sua própria imagem e da instituição em que trabalham. Para isso, segundo justificam, é necessário que haja algum monitoramento do que é veiculado nas mídias digitais pelos funcionários, prática que, na maioria das vezes, não é explicitada nos manuais de conduta. A busca de uma unidade de imagem e discurso resulta, portanto, no bloqueio à expressão individual.

Dessa forma, a instituição implanta regras de conduta para precaver-se do "mau comportamento organizacional”, insinuando daí atitudes adequadas a serem seguidas. Algumas monitoram e rastreiam as informações sobre como seus empregados se comportam em relação à marca por meio de software que estão na rede e são gratuitos. Outras instalam softwares próprios capazes não só de monitorar o uso de sua marca pelos funcionários, mas também de rastrear todos os movimentos deles na internet.

Por outro lado, muitos manuais sequer abrangem a questão do controle de informações no uso de mídias sociais. Mas isso não significa que tais instituições não se preocupam com a conduta de seus funcionários nos meios digitais. Uma hipótese é de que elas ainda não estão preparadas para lidar com as novas mídias e as suas influências nas relações de trabalho, por isso não

Gráfico 2: Indicativo do controle de informação

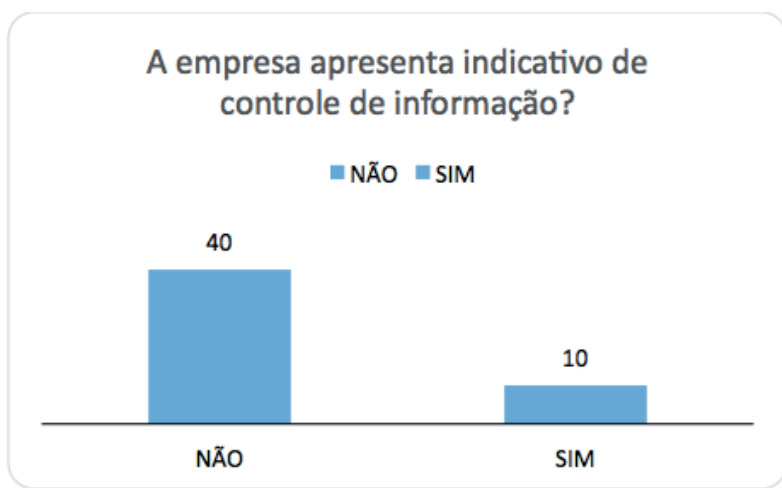

Fonte: Pesquisa Comunicação e Trabalho. Manuais de conduta das empresas como prescrição, controle e vigilância da liberdade de expressão no mundo do trabalho. 
tratam disso em seus manuais de conduta. Outra hipótese é a de que essas instituições temem se expor ou afetar sua imagem de empresas que valorizam e respeitam 0 trabalhador e, por isso, não revelam suas reais políticas de controle e vigilância nos meios digitais.

Entre os fortes indicativos de controle de informação encontrados na pesquisa, está, por exemplo, o Manual do Grupo Pão de Açúcar, no item "Segurança das Informações", onde se diz que "não é aceitável comentar informações confidenciais em locais públicos, sites de relacionamento ou fóruns de discussão na internet, em face da possibilidade de divulgação inadvertida"; ao mesmo tempo, o manual informa que "as mensagens trocadas com terceiros podem se converter em peças de processos judiciais contra os participantes". Ou seja, embora essas instituições não usem em seus manuais palavras como "controle", "punição" e "monitoramento", entre outras, existe 0 monitoramento; e é evidente que tais atitudes se reverterão em algum tipo de repreensão. Nesta ordem discursiva, a vigilância incide sobre 0 trabalhador e não 0 contrário.

Por outro lado, duas outras grandes empresas, a Votorantim e a Odebrecht, fazem questão de registrar em seus Manuais que as informações podem ser monitoradas, como segue:
A Votorantim poderá, a seu critério, usar e monitorar qualquer informação transmitida ou residente nesses meios. Essa regra abrange a informação escrita ou armazenada em sistema eletrônico e qualquer outro meio associado ${ }^{10}$.

\section{O integrante deve estar ciente de que a}

Organização tem acesso aos registros de acesso à internet, e-mail e informações armazenadas nos computadores da Organização e ao uso dos recursos de telefonia móvel e fixa da Organização. $O$ Integrante não deve ter expectativa de privacidade no que se refere a esses assuntos ${ }^{11}$.

A transparência sobre as práticas de controle, como visto anteriormente, instaura um dizer que estabelece a normalidade destas práticas, isentando as empresas de preocupação com padrões mais alinhados com a preservação ou promoção de direitos fundamentais. Ao 'avisar' o trabalhador dos riscos de transgressão, está implícita a ameaça de punição. Não se explicita tampouco como a empresa pode 'usar' a informação que detém. Outro fator que vale destacar é o controle não apenas do uso da internet nas empresas, mas de todos os equipamentos interligados à rede da companhia, os quais também podem ser acessados fora das suas dependências, como fica evidente no Manual da Hypermarcas: 


\section{A Companhia também possui o direito de} controlar $e$ monitorar o acesso à internet e de todos os equipamentos interligados ao seu sistema de tecnologia da informação (são exemplos, mas não limitados a: computadores, tablets, smartphones, telefones etc.). O seu e-mail corporativo é de propriedade da Hypermarcas e, portanto, poderá ser monitorado ${ }^{12}$.

Assim, ao circunscrever a regra no campo do direito de controle e monitoramento, a Hypermarcas atrai para si a lei. Consequentemente, a violação a esta norma é também um crime. A empresa demonstra claramente que está ancorada em jurisprudência que permite 0 controle e o monitoramento.

Na análise, também foi possível ter ideia dos procedimentos utilizados pelas instituições para monitoramento da conduta dos funcionários, como acesso irrestrito aos sistemas eletrônicos e recursos de informática que possibilitam essa vigilância constante. Porém, nem todas as instituições explicitam as formas de controle em seus manuais de conduta.

Outro ponto observado na análise é que não há um padrão nos manuais de conduta. Alguns são curtos e diretos, outros são bem mais completos e ultrapassam 20 páginas de conteúdo. Enquanto alguns são específicos para a conduta dos funcionários, outros são direcionados aos diversos públicos da instituição, como os fornecedores, sendo que estes tendem a ser mais genéricos e menos relevantes para 0 estudo.

Para a continuidade da pesquisa, devem ser exploradas outras fontes de informação, como entrevistas com responsáveis pela gestão e aplicação dos manuais de conduta nas instituições, para entender como ocorre 0 procedimento de vigilância dos funcionários. A partir desses novos dados, será realizada uma comparação dos procedimentos utilizados de fato pelas instituições para monitoramento e controle de informação e do que elas expõem em seu manual de conduta. Resta ainda sabermos: o que as instituições fazem com as informações monitoradas de seus empregados? Como são armazenadas, classificadas e personalizadas?

\section{Considerações finais}

0 levantamento e as primeiras análises de nossa pesquisa demonstram a intenção das instituições em vigiar e controlar a comunicação no mundo do trabalho, mesmo que busquem dissimular esse fato. Aquelas que adotam manuais de conduta são os 'bons exemplos', visto que a maioria das instituições ainda não adotou formas mais transparentes de tornar públicas as regras para a comunicação.

Este estudo com 50 manuais de conduta de instituições que atuam no mercado brasileiro em 
diferentes ramos produtivos e de serviços, embora em fase preliminar, faz um levantamento de dados que indicam que a privacidade do empregado e a sua liberdade de acesso à informação e 0 direito à comunicação são valores submetidos à hegemonia do valor da imagem da instituição.

Mais do que isso, os dados vão mostrando que há um novo mercado de instituições que se estrutura em torno da venda de serviços de monitoramento e controle dos dados dos empregados usuários da internet. A sofisticação dos softwares de controle, os serviços de consultoria em monitoramento do uso da internet por empregados e os manuais de conduta para o uso da internet e das redes sociais são instrumentais que evidenciam como a compreensão sobre 0 direito à informação e à liberdade de expressão está passando por um processo de transformação. 0 controle e a vigilância são um bom negócio e estão acima do direito à comunicação. Há todo um esforço discursivo dominante em naturalizar a vigilância e 0 controle, seja por meio do medo e da necessidade de segurança, seja como maneira de prevenção aos desavisados, 'incapazes' de compreender 0 valor da marca como um bem acima de tudo e de todos. Instaura-se assim um circuito em que o controle e a vigilância são instâncias que acabam com a privacidade e geram 0 medo de 0 trabalhador se expor, forçando-0 à autocensura ou a práticas de resistência. 0 esforço de silenciamento ocorre de modo indireto, integrado às normas de trabalho, e não se admite a nomeação de censura a estas práticas, o que seria incompatível com a sociedade democrática. Mesmo na área do Direito, essa discussão é muito complexa. A interpretação de que 0 direito privado das instituições se sobrepõe aos direitos fundamentais da pessoa ainda é hegemônica, conforme aponta estudo de Freitas Mello sobre o Direito de crítica do empregado nas redes sociais e a repercussão no contrato de trabalho (2015). Como se vê, o Art. 5. da Constituição Brasileira ainda é pouco conhecido e estudado e, parece-nos, há um imenso esforço de setores da sociedade para esquecê-lo.

\section{Referências}

ANDERELO, Roseane, MATOS, Maria Lucilene Dantas de. Manuais de conduta em mídias sociais e sua contribuição para a democracia digital: Um estudo de manuais brasileiros. Revista Eptic Online Vol.16 n.3 p.188-200 set.-dez., 2014.

\section{ARANTES, Julio. Centralidade da atividade} de comunicação e de trabalho: um estudo da comunicação em fábricas recuperadas por experiências autogestionárias. São Paulo: ECAUSP. Tese (Doutorado em Teoria e Pesquisa em Comunicação) - Escola de Comunicações e Artes, Universidade de São Paulo, São Paulo, 2015.

BARRY, Bruce. Speechless: the erosion of free expression in the american workplace. San Francisco: Berret-Koehler Publishers, Inc, 2007.

B0UTET, Josiane (org.). Paroles au travail. Paris : L’Hamattan, 1995. . La vie verbale au travail. Des manufactures aux centres d'apples. Tolouse : Octares, 2008.

BRUNO, Fernanda. Dispositivos de vigilância no 
ciberespaço: duplos digitais e identidades simuladas. Revista Fronteiras. Estudos midiáticos. VIII(2): 152159, maio/agosto 2006.

Monitoramento, classificação e controle nos dispositivos de vigilância digital. In: ANTOUN, Henrique. (org.) Web2.0 Participação e vigilância na era da comunicação distribuída. Rio de Janeiro: Mauad, 2008.

CHIAVENATO, Idalberto (1995). Introdução à teoria geral da administração. $4^{\mathrm{a}}$ ed. Rio de Janeiro; Markon. CONSTITUIÇÃO DA REPÚBLICA FEDERATIVA DO BRASIL, 1988. Disponível em: http://www.planalto.gov. br/ccivil_03/Constituicao/Constituicao.htm Acesso: $12 / 9 / 2015$

COSTA, Cristina (org.). A censura em debate. São Paulo: ECA-USP, 2014.

. Diálogos sobre censura e liberdade de expressão. Brasil e Portugal. São Paulo: ECA-USP, 2014.

COSTA, Rogério da. Sociedade de controle. São

Paulo Perspec., São Paulo, v. 18, n. 1, p. 161-

167, Mar. 2004 . Disponível em: < http://www. scielo.br/scielo.php?script $=$ sci_arttext\&pid $=\mathrm{S} 0102$ $88392004000100019 \& \operatorname{lng}=$ en\&nrm $=$ iso $>$. Acesso $26 / 9 / 2015$

DELEUZE, Gilles. Post-Scriptum sobre as sociedades de controle. In: Conversações. SP: Editora 34, 1992.

FIGAR0, Roseli. Vigilância e controle à comunicação no mundo do trabalho. In: Costa, Cristina (org.). Diálogos sobre Censura e Liberdade de expressão. Brasil e Portugal. São Paulo: ECA-USP, 2014. 0 mundo do trabalho e as organizações: abordagens discursivas de diferentes significados. Revista Organicom. Revista Brasileira de Comunicação Organizacional e Relações Públicas. São Paulo: ECAUSP, v. 5, n.9, 2008a.

. Relações de comunicação no mundo do trabalho. São Paulo: Anna Blume, 2008b.
FOUCAULT, Michel. Em defesa da sociedade: curso no Collège de France (1975-1976). São Paulo: Martins Fontes, 2000.

0 que é um autor? ( $3^{\mathrm{a}}$ ed.).

Lisboa: Vega, 1992

Vigiar e Punir: nascimento da

prisão. 20ª ed. Petrópolis: Vozes, 1999.

FUCHS, Christian. Political, Economy and

Surveillance Theory. Critical Sociology

0896920511435710, April 2, 2012. Disponível em http://

fuchs.uti.at/wp-content/MarxSurveillance.pdf

GRAMSCI, Antonio. Obras escolhidas. São Paulo:

Martins Fontes, 1978.

LACOSTE, Michele. Parole. Activité, situation. In: BOUTET, Josiane (org.). Paroles au travail. Paris:

L’Hamattan, 1995.

LYON, David. Liquid surveillance: The contribution of Zygmunt Bauman to surveillance studies. International Political Sociology. 4, 325-338, 2010.

MARX, Karl. Capital y tecnologia: manuscritos inéditos (1861-1863). San Francisco, México: Terra Nova, 1980

MELLO, Cristiane Maria Freitas. Direito de crítica do empregado nas redes sociais e a repercussão no contrato de trabalho. São Paulo: LTR, 2015.

NEGRI, A. e HARDT, M. Império. Tradução de Berilo Vargas. Rio de Janeiro, Record, 2001.

NOMURA, Maria Carolina. Demissão por comentário em rede social gera polêmica. Não há separação pessoal x profissional na web, diz consultor. iG São Paulo. 17/05/2010. Disponível em: http://economia. ig.com.br/carreiras/demissao-por-comentario-em-redesocial-gera-polemica/n1237729612130.html Acesso: $15 / 08 / 2015$.

ORLANDI, Eni. As formas do silêncio: no movimento dos sentidos. Campinas: Unicamp, 1992. 
Discurso e Texto. Campinas: Pontes, 2001.

PINTO, Álvaro Vieira. 0 conceito de tecnologia. vol. I e

II. Rio de Janeiro: Contraponto, 2005.

REBECHI, Claudia Nociolini. Prescrições de

comunicação e racionalização do trabalho: os

ditames de relações públicas em diálogo com o discurso

do IDORT (anos 1930-1960). 2014. Tese (Doutorado

em Teoria e Pesquisa em Comunicação) - Escola de

Comunicações e Artes, Universidade de São Paulo, São

Paulo, 2014. Disponível em: < http://www.teses.usp.br/ teses/disponiveis/27/27152/tde-20102014-110342/> .

Acesso em: 2015-09-18.

ROSSI-LANDI, Fierruccio. A linguagem como

trabalho e como mercado. Uma teoria da produção e da alienação linguísticas. São Paulo: Difel, 1985.

SANTOS, Milton. SILVEIRA, María Laura. 0 Brasil.

Território e sociedade no início do século XXI. Rio

de Janeiro: Record, 2001.

SANTOS, Milton. Por uma outra globalização: do pensamento único à consciência universal. $3^{\mathrm{a}} \mathrm{ed}$. Rio de Janeiro: Record, 2000

SCHWARTZ, Yves, DURRIVE, Louis. Trabalho e

Ergologia. Niterói: EDUFF, 2007.

SENNET, Richard. A corrosão do caráter. 0

desaparecimento das virtudes com o novo capitalismo.

Rio de Janeiro: Best Bolso, 2012.

SURVEILLANCE \& SOCIETY. Disponível em: http:// library.queensu.ca/ojs/index.php/surveillance-andsociety/index Acesso: 12/09/2015.

TIC DOMICÍLIO E EMPRESAS 2013. Pesquisa sobre 0 Uso das Tecnologias de Informação e Comunicação no Brasil. Comitê Gestor da Internet no Brasil. Disponível em: http://www.cgi.br/media/docs/publicacoes/2/ TIC_DOM_EMP_2013_livro_eletronico.pdf > Acesso: 11/04/2015.

WEBER, Max. A ética protestante e o espírito do capitalismo. 14ª ed. São Paulo: Pioneira, 1999. 


\section{Surveillance and control of the communication at world of the work: manuals of conduct model communication}

\section{Abstract}

This article aims to present the theoretical and methodological aspects of research conducted by Research Center in Communication and Work ECAUSP. The study aims to map and analyze the technical and administrative procedures for companies to track, monitor and control communication relationships in the world of the work, especially through social media. The mapping is being done out based on the analysis of the conduct of private and public companies manuals. Preliminary results show the ambiguity between those manuals that explain the existence of monitoring and control and those that it will hide these procedures.

\section{Keywords}

Communication. Surveillance. World of work.

\section{Vigilancia y control de la} comunicación en el mundo del trabajo: manuales de conducta modelan la comunicación

\section{Resumen}

Este artículo tiene como objetivo presentar los aspectos teóricos y metodológicos de la investigación llevada a cabo por el Centro de Investigación en Comunicación y Trabajo de la ECA-USP. El estudio pretende analizar los procedimientos técnicos y administrativos para las empresas realizar el seguimiento, vigilar y controlar las relaciones de comunicación en el mundo del trabajo, especialmente por lo medio de las medias sociales. El mapeo es basado en el análisis de los manuales de conducta de empresas públicas y privadas. Resultados preliminares muestran la ambigüedad entre los manuales que explican la existencia de vigilancia y control y los que se esconden estos procedimientos.

\section{Palabras clave}

Comunicación. Vigilancia. Mundo del trabajo. 


\section{Expediente}

A revista E-Compós é a publicação científica em formato eletrônico da Associação Nacional dos Programas de Pós-Graduação em Comunicação (Compós). Lançada em 2004, tem como principal finalidade difundir a produção acadêmica de pesquisadores da área de Comunicação, inseridos em instituições do Brasil e do exterior.

\section{E-COMPÓS I www.e-compos.org.br I E-ISSN 1808-2599}

Revista da Associação Nacional dos Programas de Pós-Graduação em Comunicação.

Brasília, v.18, n.3, set./dez. 2015.

A identificação das edições, a partir de 2008, passa a ser volume anual com três números.

Indexada por Latindex I www.latindex.unam.mx

\section{CONSELHO EDITORIAL}

Alexandre Farbiarz, Universidade Federal Fluminense, Brasil Alexandre Rocha da Silva, Universidade Federal do Rio Grande do Sul, Brasil Ana Carolina Damboriarena Escosteguy, Pontifícia Universidade Católica do Rio Grande do Sul, Brasil

Ana Carolina Rocha Pessôa Temer, Universidade Federal de Goiás, Brasil Ana Regina Barros Rego Leal, Universidade Federal do Piauí, Brasil Andrea França, Pontifícia Universidade Católica do Rio de Janeiro, Brasil André Luiz Martins Lemos, Universidade Federal da Bahia, Brasil Antonio Carlos Hohlfeldt, Pontifícia Universidade Católica do Rio Grande do Sul, Brasil

Arthur Ituassu, Pontifícia Universidade Católica do Rio de Janeiro, Brasil Álvaro Larangeira, Universidade Tuiuti do Paraná, Brasil Ângela Freire Prysthon, Universidade Federal de Pernambuco, Brasil César Geraldo Guimarães, Universidade Federal de Minas Gerais, Brasil Cláudio Novaes Pinto Coelho, Faculdade Cásper Líbero, Brasil Daisi Irmgard Vogel, Universidade Federal de Santa Catarina, Brasil Denize Correa Araujo, Universidade Tuiuti do Paraná, Brasil Eduardo Antonio de Jesus, Pontifícia Universidade Católica de Minas Gerais, Brasil

Daniela Zanetti, Universidade Federal do Espirito Santo, Brasil Eduardo Vicente, Universidade de São Paulo, Brasil Elizabeth Moraes Gonçalves, Universidade Metodista de São Paulo, Brasil Erick Felinto de Oliveira, Universidade do Estado do Rio de Janeiro, Brasil Francisco Elinaldo Teixeira, Universidade Estadual de Campinas, Brasil Francisco Paulo Jamil Almeida Marques, Universidade Federal do Paraná, Brasil

Gabriela Reinaldo, Universidade Federal do Ceará, Brasil Goiamérico Felício Carneiro Santos, Universidade Federal de Goiás, Brasil Gustavo Daudt Fischer, Universidade do Vale do Rio dos Sinos, Brasil Herom Vargas, Universidade Municipal de São Caetano do Sul, Brasil Itania Maria Mota Gomes, Universidade Federal da Bahia, Brasil
Janice Caiafa, Universidade Federal do Rio de Janeiro, Brasil Jiani Adriana Bonin, Universidade do Vale do Rio dos Sinos, Brasil José Afonso da Silva Junior, Universidade Federal de Pernambuco, Brasil José Luiz Aidar Prado, Pontifícia Universidade Católica de São Paulo, Brasil Juçara Gorski Brittes, Universidade Federal de Ouro Preto, Brasil Kati Caetano, Universidade Tuiuti do Paraná, Brasil

Lilian Cristina Monteiro França, Universidade Federal de Sergipe, Brasil Liziane Soares Guazina, Universidade de Brasília, Brasil Luíza Mônica Assis da Silva, Universidade de Caxias do Sul, Brasil Luciana Miranda Costa, Universidade Federal do Pará, Brasil Malena Segura Contrera, Universidade Paulista, Brasil Maria Ogécia Drigo, Universidade de Sorocaba, Brasil Maria Ataide Malcher, Universidade Federal do Pará, Brasil Marcia Tondato, Escola Superior de Propaganda e Marketing, Brasil Marcel Vieira Barreto Silva, Universidade Federal da Paraíba, Brasil Maria Clotilde Perez Rodrigues, Universidade de São Paulo, Brasil Maria das Graças Pinto Coelho, Universidade Federal do Rio Grande do Norte, Brasil

Mauricio Ribeiro da Silva, Universidade Paulista, Brasil

Mauro de Souza Ventura, Universidade Estadual Paulista, Brasil Márcio Souza Gonçalves, Universidade do Estado do Rio de Janeiro, Brasil Micael Maiolino Herschmann, Universidade Federal do Rio de Janeiro, Brasil Mirna Feitoza Pereira, Universidade Federal do Amazonas, Brasil Nísia Martins Rosario, Universidade Federal do Rio Grande do Sul, Brasil Potiguara Mendes Silveira Jr, Universidade Federal de Juiz de Fora, Brasil Regiane Regina Ribeiro, Universidade Federal do Paraná, Brasil Rogério Ferraraz, Universidade Anhembi Morumbi, Brasil Rose Melo Rocha, Escola Superior de Propaganda e Marketing, Brasil Rozinaldo Antonio Miani, Universidade Estadual de Londrina, Brasil Sérgio Luiz Gadini, Universidade Estadual de Ponta Grossa, Brasil Simone Maria Andrade Pereira de Sá, Universidade Federal Fluminense, Brasil Veneza Mayora Ronsini, Universidade Federal de Santa Maria, Brasil Walmir Albuquerque Barbosa, Universidade Federal do Amazonas, Brasil

\section{COMISSÃO EDITORIAL}

Cristiane Freitas Gutfreind

Pontifícia Universidade Católica do Rio Grande do Sul, Brasil

Irene Machado

Universidade de São Paulo, Brasil

\section{CONSULTORES AD HOC}

Claudia Peixoto de Moura, Pontificia Universidade Católica do Rio Grande do Sul, Brasil Francisco Rüdiger, Pontifícia Universidade Católica do Rio Grande do Sul, Brasil Juremir Machado da Silva, Pontifícia Universidade Católica do Rio Grande do Sul, Brasil Maria Aparecida Baccega, Universidade de São Paulo, Brasil

Roberto Tietzmann, Pontifícia Universidade Católica do Rio Grande do Sul, Brasil

\section{EQUIPE TÉCNICA}

ASSISTENTE EDITORIAL I Márcio Zanetti Negrini

REVISÃO DE TEXTOS I Press Revisão

EDITORAÇÃO ELETRÔNICA I Roka Estúdio

CONTATO I revistaecompos@gmail.com
COMPÓS I www.compos.org.br

Associação Nacional dos Programas de Pós-Graduação em Comunicação

Presidente

Edson Fernando Dalmonte

Programa de Pós-Graduação em Comunicação

e Cultura Contemporânea - UFBA

edsondalmonte@uol.com.br

Vice-presidente

Cristiane Freitas Gutfreind

Programa de Pós-Graduação em Comunicação Social - PUC-RS cristianefreitas@pucrs.br

Secretário-Geral

Rogério Ferraraz

Programa de Pós-Graduação em Comunicação

Universidade Anhembi Morumbi

rogerioferraraz@anhembimorumbi.edu.br 